\title{
Three-dimensional Numerical Simulation on Stilling Basin of Sluice in Low Head
}

\author{
Yuehua WANG ${ }^{1,2}$, Bin WANG ${ }^{1,2}$, Hongqing ZHANG ${ }^{1,2}$, Ziming \\ WANG $^{1,2}$, Shengzhi ZHOU ${ }^{1,2}$, Long YE ${ }^{1,2}$ \\ 1.Zhejiang Institute of Hydraulics and Estuary, Hangzhou, China \\ 2.Key Laboratory of Estuarine and Coast of Zhejiang Province, Hangzhou, China
}

\begin{abstract}
KEYWORDS: Sluice; Stilling basin; RNG turbulence model; Numerical simulation
ABSTRACT: Combined with design and test data of a low head sluice, CFD software and RNGturbulence model were used to simulate three-dimensional flow of sluices stilling basin. The original design has been optimized by adjusting the layout of the stilling basin. In connection with typical operating conditions, the calculated results such as sluice discharge capacity, flow pattern, velocity distribution, and the water surface line are more consistent with the observations of the physical model. Further analysis based on turbulent energy distribution in stilling basin, the energy dissipation rate, reveals that the two stilling basin can improve energy dissipation efficiency of water jump with low Froude number. Optimization scheme is effective and feasible, and it also provides a good reference for future mathematical model for the design and optimization of such works.
\end{abstract}

\section{INTRODUCTION}

The safety of shipping, flood discharging and energy dissipation is a very important issue in hydraulic engineering, especially in cases of low water head. Low head sluice is widely used in shipping improvement, flood control and ecological environment protection, which has the characteristics of low-head, large unit discharge, and low energy dissipation.

Energy dissipation method of low head sluice is often the underflow energy dissipation with stilling basin, which keeps close relationship with inflow Fr value. Energy dissipation of low head sluice is inadequate due to smaller $\operatorname{Fr}(2.5<\operatorname{Fr}<4.5)$. When the $\operatorname{Fr}<4.5$, the energy dissipation is only $20 \% \sim 45 \%$. A lot of energy is brought to downstream, which result in river-bed scour. The characteristics of underflow energy dissipation has been studied, and it is found that the required tail-water level to ensure the hydraulic jump can be reduced and the flow pattern in downstream is stable. It is also found that the relative energy loss in the stilling basin is larger than that in the sudden enlargement type basin (Katakam V., 1998).

Two stilling basins with submerged hydraulic jump is a good type of energy dissipater. They have features of better energy dissipation ratio and stable flow pattern. Owing to the complex flow pattern and vortex structure in the stilling basins, the more effective methods to finalize the relevant dimensions of sluice are theoretical calculation and the hydraulic model test. However, the hydraulic model test is of long cycle and high cost (Chen 2005). Numerical simulation can provide a good supplement to physical model tests and be used to obtain the detailed hydraulic characteristics of the velocity field.

With the development of the computer technology, the application of turbulence models plays an important part in studying the problems of hydraulics. The $k-\varepsilon$ two-equation turbulence model is an useful tool in simulating this complex water flow (Xu et al., 1996, Lu et al., 2008, Pan 2008, Chen et al., 2008). Fluent and Flow-3D software are useful tool in 3D simulation (Shi 2010, Wang et al., 2012). In this study, the characteristics of the hydraulic jumps in two stilling basins are studied by using 3D RNG $k-\varepsilon$ turbulence model of Flow-3D. According to related design and test data of a sluice, discharge capacity, flow pattern, velocity distribution, water surface line and turbulent kinetic energy distribution in the stilling basin have been computed that provide a reference for engineering design and optimization. 


\section{PROJECT SUMMARY}

Original design of one stilling basin: stilling basin is $26.5 \mathrm{~m}$ long, $1.60 \mathrm{~m}$ deep. The elevation of slab is $-2.60 \mathrm{~m}$, elevation of end sill is $-1.00 \mathrm{~m}$. The apron is $20.0 \mathrm{~m}$ long, with a little slope and elevation of end is $-1.20 \mathrm{~m}$. The anti-scour trench is $20.0 \mathrm{~m}$ long, and elevation of end is $-3.00 \mathrm{~m}$, as the same as the downstream river elevation.

Optimization scheme of two stilling basins : in order to increase the energy dissipated ratio in the stilling basin and improve the water flow pattern in stilling basin and downstream, optimization solution is set as two stilling basins. First stilling basin is $20 \mathrm{~m}$ long, $1.50 \mathrm{~m}$ deep. Its bottom elevation is $-3.00 \mathrm{~m}$, and elevation of end sill is $-1.50 \mathrm{~m}$. Second pool is $20 \mathrm{~m}$ long, $1.00 \mathrm{~m}$ deep. Its slab elevation is $-3.50 \mathrm{~m}$, and end sill elevation is $-2.50 \mathrm{~m}$. the elevation of downstream river is dredged to $-2.50 \mathrm{~m}$.

Figure 1 is profile of the stilling basin of original design plan and optimization scheme. Considering the adverse conditions, calculation conditions are shown in table 1.

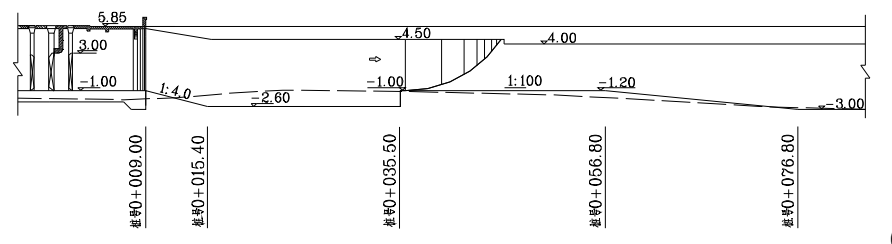

(a)

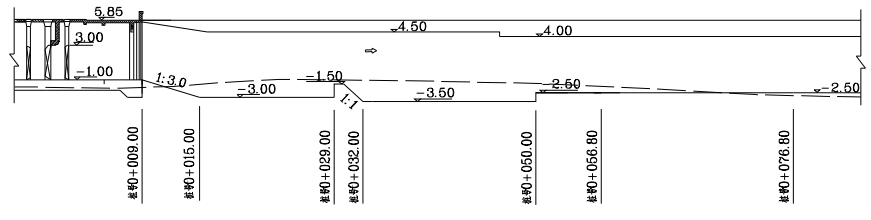

(b)

Figure 1 Profile of stilling basin; (a)Original design; (b)Optimization scheme.

Table 1 Calculation conditions

\begin{tabular}{lcc}
\hline \multirow{2}{*}{ upstream } & Description & number \\
\cline { 2 - 3 } & design flood level & $4.17 \mathrm{~m}$ \\
\cline { 2 - 3 } downstream & check flood level & $4.26 \mathrm{~m}$ \\
\cline { 2 - 3 } & mean low water level & $-1.64 \mathrm{~m}$ \\
\hline
\end{tabular}

\section{MATHEMATICAL MODEL}

\section{Governing equations}

RNG $k-\varepsilon$ turbulence model is used to calculate the hydraulic parameters of the flows. Numerical simulation equations include continuity equation, momentum equation, $k$ equation, $\varepsilon$ equation.

Continuity equation: $\frac{\partial u_{i}}{\partial x_{i}}=0$

Momentum equation: $\frac{\partial u_{i}}{\partial t}+u_{j} \frac{\partial u_{i}}{\partial x_{j}}=f_{i}-\frac{1}{\rho} \frac{\partial p}{\partial x_{i}}+\frac{\partial}{\partial x_{j}}\left[\left(v+v_{t}\right)\left(\frac{\partial u_{i}}{\partial x_{j}}+\frac{\partial u_{j}}{\partial x_{i}}\right)\right]$

Turbulent kinetic energy equation: $\frac{\partial k}{\partial t}+\frac{\partial\left(k u_{i}\right)}{\partial x_{i}}=\frac{\partial}{\partial x_{i}}\left[\left(v+v_{t}\right) \frac{\partial k}{\partial x_{i}}\right]+G_{k}-\varepsilon$

Turbulent kinetic energy dissipation rate equation:

$$
\frac{\partial \varepsilon}{\partial t}+\frac{\partial\left(\varepsilon u_{i}\right)}{\partial x_{i}}=\frac{\partial}{\partial x_{i}}\left[\left(v+v_{t}\right) \frac{\partial \varepsilon}{\partial x_{i}}\right]+C_{\varepsilon 1}^{*} \frac{\varepsilon}{k} G_{k}-C_{\varepsilon 2} \frac{\varepsilon^{2}}{k}
$$


Where $v_{t}$ is the eddy viscosity coefficient obtained through the turbulent kinetic $k$ and the turbulent dissipation rate $\varepsilon, v_{t}=C_{\mu} \frac{k^{2}}{\varepsilon} \cdot C_{\varepsilon 1}^{*}=C_{\varepsilon 1}-\frac{\eta\left(1-\eta / \eta_{0}\right)}{1+\beta \eta^{3}}, \quad \eta=S k / \varepsilon, \quad S=\left(2 \overline{S_{i j}} \overline{S_{i j}}\right)^{1 / 2}$, In the tensor expression, $i$ and $j$ are used as the summation subscripts.

Free water surface

VOF method is the effective method of dealing with the complex free surface put forward by Hirt and Nichols in 1981, which is widely applied in numerical simulation of tracing free surface.

This method defines the fluid volume function $F=F(x, y, z, t)$, which means the ratio of volume of fluid in computational domain. For a unit, $F=1$ indicates the unit is completely filled with fluid. $F=0$ indicates that the unit cell is empty, no fluid. $F=1 \sim 0$ indicates the unit is filled with the fluid partly.

$$
\frac{\partial F}{\partial t}+\frac{\partial\left(F u_{i}\right)}{\partial x_{i}}=0
$$

Grid generation, boundary condition and initial condition

Grid generation

The model region is established using AUTOCAD software, upstream section is $150 \mathrm{~m}$ long, downstream section is $100 \mathrm{~m}$ long from anti-scour trench. The numerical simulation covers the upstream river, the stilling basin, and the downstream reach.

Free mesh method and structured orthogonal grid is used to computing area, and local area is of gradient encryption. In order to control the total number of grid, the upstream channel, lock chamber and downstream river are meshed respectively. Grid number of upstream channel is about 160000 , total grid of downstream river is about 220000. Grid of original design lock chamber is about 780000 , and that of optimization is about 1.2 million. The calculation region and the computing grid are shown in Figure 2 and Figure 3.

\section{Boundary conditions}

Inflow boundary: based on pressure boundary, water level values on the inflow boundary must be given, such as design or check flood level.

Outflow boundary: the pressure boundary conditions are given on the exit of the calculation region, and the corresponding water level is set on the outflow boundary.

Wall boundary: using the wall-function method.

\section{Initial conditions}

Setting the initial water region and giving initial water level with hydrostatic pressure. The initial time step is set to $0.002 \mathrm{~s}$, the minimum time step is set to $0.000001 \mathrm{~s}$.
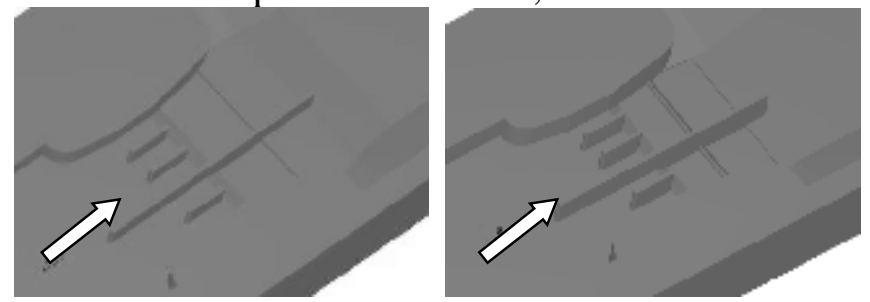

(a)

(b)

Figure 2 Numerical simulation region of sluice chamber; (a)Original design; (b)Optimization scheme.
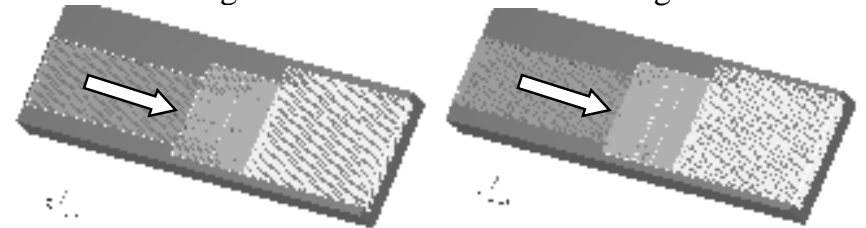

(a)

(b)

Figure 3 Mesh of simulation region; (a)Original design; (b)Optimization scheme. 


\section{RESULTS AND DISCUSSION}

\section{Discharge capacity}

Discharge capability of free discharging: 5 gates are fully open.

Based on physical model test data, stage-discharge relation can be expressed as

$$
Q=62.265(Z+1.00)^{1.579}
$$

According to the calculated data, stage-discharge relation can be expressed as

$$
Q=66.644(Z+1.00)^{1.533}
$$

In which $Q$ is drainage quantity, $\mathrm{m}^{3} / \mathrm{s} ; Z$ is inland water level, $\mathrm{m} ;-1.00$ is slab elevation of sluice, $\mathrm{m}$.

Figure 4 shows the fitting curve between calculated value and measured value. It can be seen from the chart that the measured values is very close to calculated values.

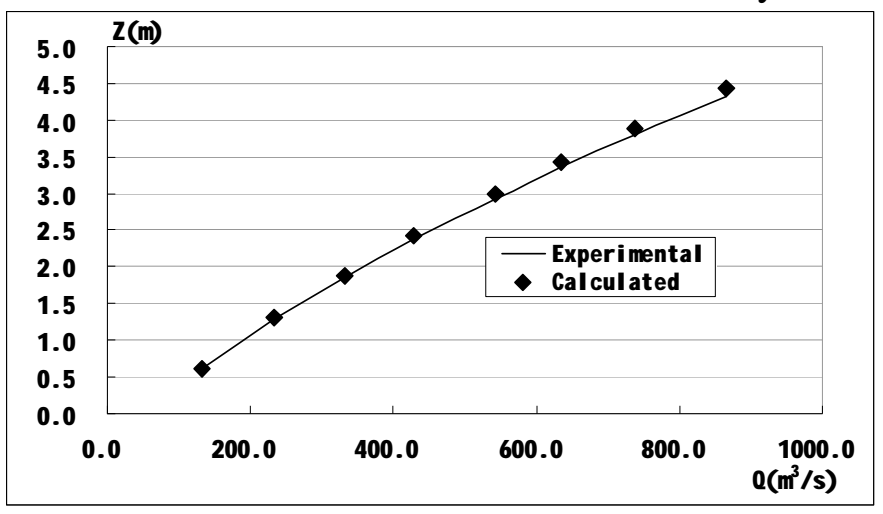

Flow pattern

Figure 4 Stage-discharge relations for free discharging

Original design

It can be seen from Figure 5 that the computed flow pattern agrees very well with that measured from the physical model. For a certain discharge and tailwater level, the hydraulic jump was entirely located in the stilling basin. Through stilling basin, the flow spread quickly with obvious phenomenon of shock wave. At the end of the stilling basin, the velocity of water flow is large and water depth is nonuniform along transect. In check condition, current has kept its velocity higher at the end of anti-scour trench.

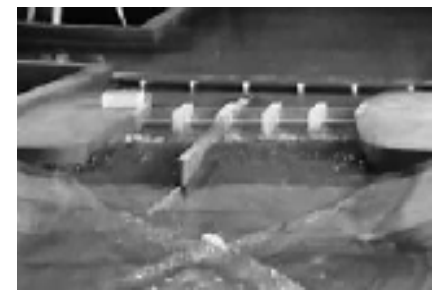

(a)

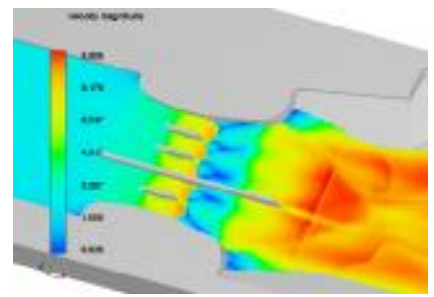

(b)

Figure 5 Flow patterns under check condition; (a) physical model; (b) mathematical model.

\section{Optimization scheme}

It can be seen from Figure 6 that the submerged hydraulic jump in stilling basin agrees well with the measured. The strong aerated water in the foreside of the stilling basin is turbulent and the free water surface fluctuates greatly and randomly. Hydraulic jump is occurred in the first stilling basin completely. Then the flow enter slope section of the second stilling basin through first stilling basin section, submerged hydraulic jump is also forced successfully. After stilling basin, the flow evenly spread. Water depth is uniform along transect and there is no obvious phenomenon of shock wave. The computed maximum vertical mean velocity at the end of anti-scour trench is lower than that of the original design. It is said that the energy dissipation effect is improved. 

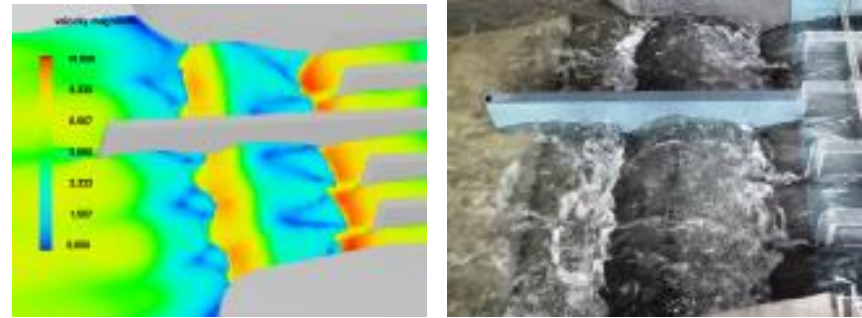

(a)

(b)

\section{Velocity}

Figure 6 Flow patterns under check condition; (a) physical model; (b) mathematical model.

The mathematical velocity of horizontal and longitudinal profile can better reflect the flow along stilling basin (Figure 7 and Figure 8 ). The velocity measuring points are about $0.1 \mathrm{~m}$ from the end sill elevation of the stilling basin. Due to the existence of the two stilling basins of optimization, the flow pattern in the stilling basin has stronger three-dimensional features.

It can be seen from Figure 7 that the maximum velocity at the end of anti-scour trench of the original design reaches $8 \mathrm{~m} / \mathrm{s}$ approximately, and flow velocity distribution is nonuniform. As for optimization, two stilling basins strengthen the water mixing obviously. After the second stilling basin, flow velocity decreases sharply. The maximum velocity at the end of anti-scour trench reaches $4 \mathrm{~m} / \mathrm{s}$. It also can be seen from Figure 8 that flow velocity near the slab of optimization is smaller than that of original design. It is said that two stilling basins can effectively reduce the water flow velocity at the downstream river and make velocity distribution more uniform.

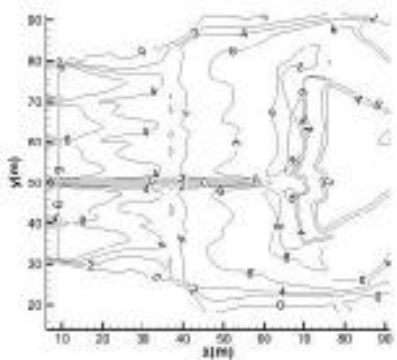

(a)

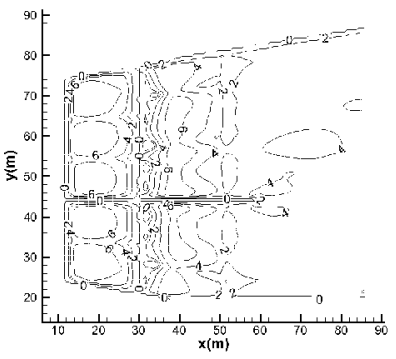

(b)
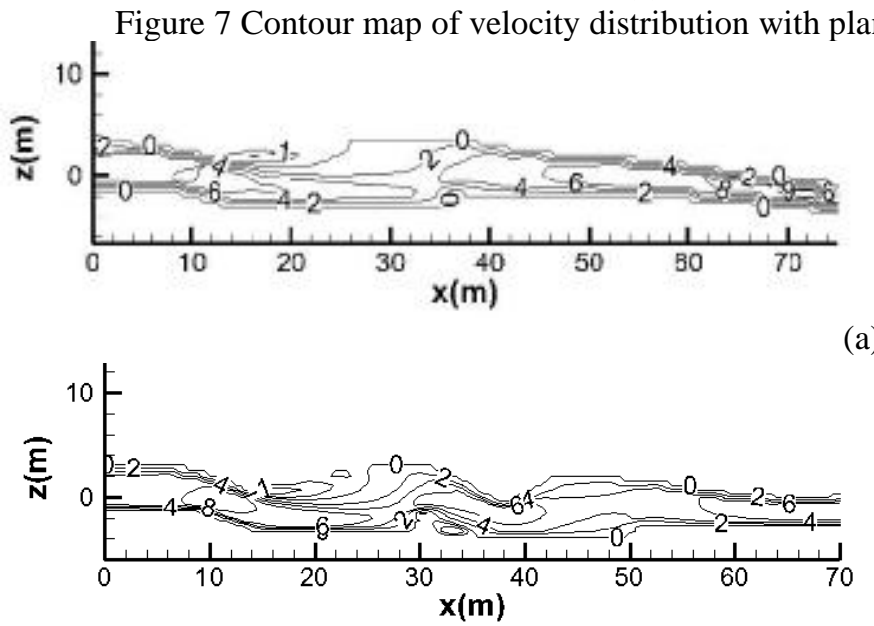

(a)

(b)

Figure 8 Contour map of velocity distribution with center section; (a)Original design;(b)Optimization scheme. Water surface profile

Figure 9 and Figure 10 show the simulated and measured results of the water surface profile along the stilling basin. The computed results are in good agreement with that of model test, it further illustrates the reliability of the mathematical model, and it can reflect the real flow structure and characteristics. 


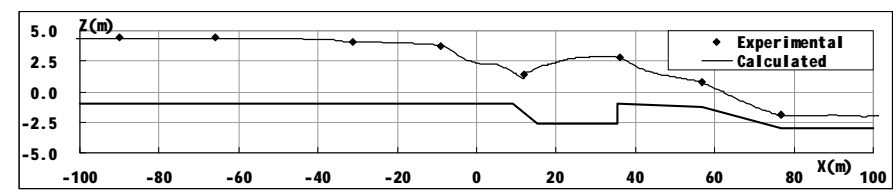

Figure 9 Water surface profile of original design under check condition

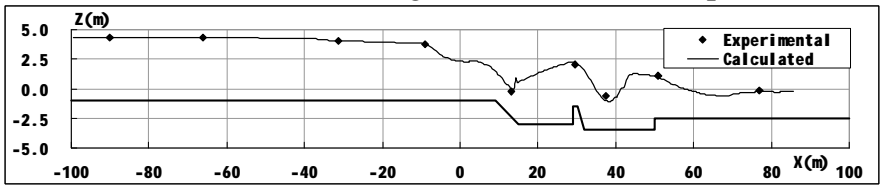

Figure 10 Water surface profile of optimization under checkcondition

Energy loss ratio

The energy loss ratio could be expressed as follows

$$
\mathrm{K}_{\mathrm{j}}=\frac{E_{1}-E_{2}}{E_{1}} \times 100 \%
$$

From figure (8) the specific energy at the beginning of the jump $\left(E_{l}\right)$, and at the end of the jump $\left(E_{2}\right)$ can be written as:

$$
E_{1}=\mathrm{H}_{1}+\frac{V_{1}^{2}}{2 g}-Z_{0} 、 E_{2}=\mathrm{H}_{2}+\frac{V_{2}^{2}}{2 g}-Z_{0}
$$

Under design condition, energy loss ratio of the original design and optimization is $27.4 \%$, $49.6 \%$ respectively. When under check condition, the energy dissipation ratio of the original design and optimization is $21.7 \%, 45.4 \%$ respectively. Energy loss ratio of the optimization is better.

The distributions of the turbulent kinetic energy are shown in Figure 11 and Figure 12. It can be seen that the turbulent kinetic energy takes the maximum on the foreside of the stilling basin, and then gradually declines along the slab of the stilling basin. Near the foreside of the stilling basin, the flow is strongly turbulent and most of the energy is dissipated. The energy dissipation is very weak at the end of the stilling basin.

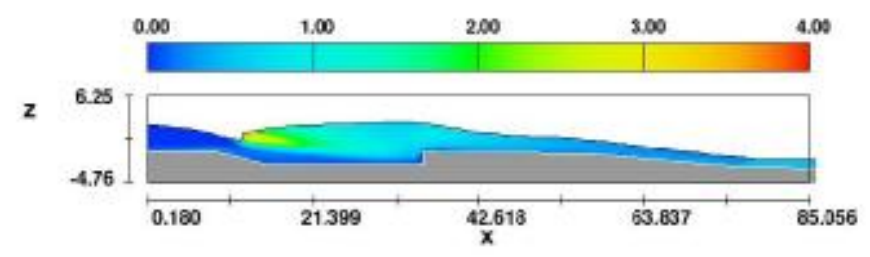

(a)

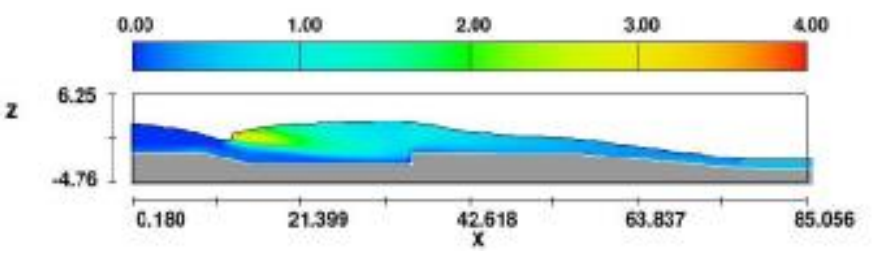

(b)

Figure 11 Distributions of turbulent kinetic energy for original design; (a)Design condition; (b)Check condition.

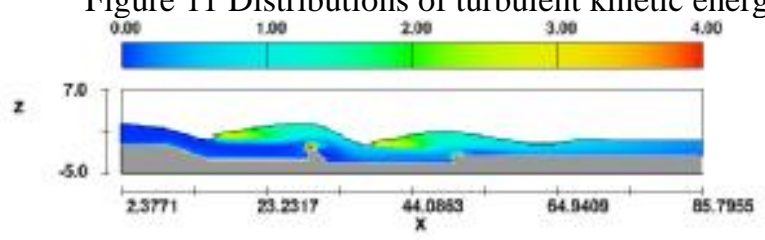

(a)

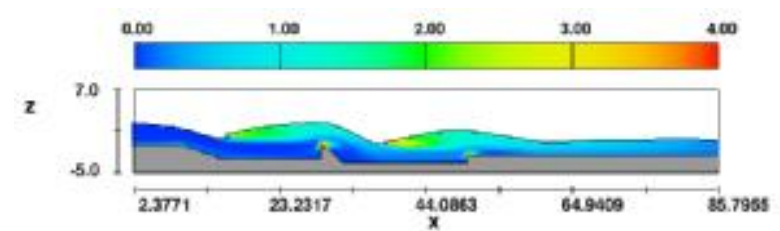

(b)

Figure 12 Distributions of turbulent kinetic energy for optimization; (a)Design condition; (b)Check condition. 


\section{CONCLUSIONS}

The numerical simulation is carried out for the stilling basin of low head sluice, as is in a practical project with original and optimum scheme. The characteristics of the hydraulic jump in a stilling basin are studied by using RNG turbulence models of Flow-3D in this article, and the numerical simulation results are verified by a series of model experiments. The conclusions are as follows:

(1) 3-D numerical simulations are carried out for the water flow in a stilling basin. The calculated results, such as discharge capacity, flow pattern, velocity, and water surface profile are in good agreement with those obtained by experiments. It indicates that the turbulence models are valid.

(2) The energy loss ratio is calculated, and results show that two stilling basins can increase the energy dissipation. Besides, the turbulent kinetic energy distribution is also simulated by using turbulence mode, and simulated results agree better with the practical situation of the water flow movement.

\section{References}

[1] Katakam V. 1998. Spatial B-jump at channel enlargements with abrupt drop. Journal of Hydraulic Engineering, ASCE, 124(6).

[2] Chen J.Y. 2005. Experimental researchon enegry dissipater of diversion works in Low Head. Northwest A\&F University.

[3] Xu W.L., Liao H.S. and Yang Y.Q. et al. 1996. Numerical simulation of 3-D turbulent flows of plunge pool and energy dissipation analysis. Journal of Hydrodynamics, Ser. A, 11(5): 561-569.

[4] Lu L. and Li Y.C. 2008. Numerical simulation of turbulent free surface flow over obstruction. Journal of Hydrodynamics, 20(4): 414-423.

[5] Pan Z.L. 2008. Numerical simulationof free surface in a stilling basinof sluice. Zhejiang Hydrotechnics, (11): 25-27.

[6] Chen C., Wei W.L.and Yan J.J. 2008. Two Dimensional Numerical Simulation of Hydraulic Jump Behind Sluice Based On Fluent. Journal of Heilong jiang Hydraulic Engineering, 34(3): $17-23$.

[7] Shi Z.P. 2010. Numerical simulation of energy dissipater with low-head flood discharging structure. Northwest A\&F University.

[8] Wang Y.H. Bao Z.J. and Wang B. 2012. Three Dimensional Numerical Simulation of Flow in Stilling Basin Based On Flow-3D. Engineering journal of wuhan university, 45(4): 454-457. 